\title{
Phase Separation of Water in Oil Emulsion Using Electro-Pulse Inductive Coalescer
}

\author{
Ezadin. B. Farhat Alkateb*, Dr. Satyendra Nath, Prof. A. K. Nema \\ *Research Scholar, Department of Environmental Science, SHIATS-Deemed University, Allahabad 211007, U.P, India \\ Assistant Professor, Department of Environmental Science, SHIATS-Deemed University, Allahabad-211007, U.P, India \\ Co-Advisor, Professor, Department of Civil Engineering, IIT-Delhi, HauzKhas, New Delhi
}

\begin{abstract}
An initial study of the effect of electrostatics on coalescence has been made with the view of improving the separation process in liquid-liquid dispersion. The equipment's used were a laboratory scale mixing device, electrostatic Coalescer with gravity settler and a Lasentec device. Rapid breakage of liquid membrane emulsions is attractive for the industrial application of liquid membrane extraction and in Crude oil dehydration and desalting. The electrostatic emulsion breakage process was investigated with regard to its parameters. The outcome gives an idea about the breakage efficiency, which increases with strength of applied field, frequency, and attainable polarization of the membrane phase molecules. The separation of water-in-oil emulsion is achieved by using AC, DC, pulsed DC electric field. Mechanistically, each field type performs differently in promoting phase separation by droplet coalescence.
\end{abstract}

Keywords: Emulsion; separation; coalescence; electrostatic; water-in-oil emulations

\section{Introduction}

Mixing and separation of section should give by the system of any solvent extraction. To extend the precise surface space, it necessary to disperse one section (the dispersed phase) within the alternative (continues phase), so as to get considerable levels of mass transfer. The 2 phases should then be separated. In solvent extraction, but this separation of phases has usually been a retardant.

For the blending and separation of phases amongst that are columns and mixer-settlers, there are differing types of apparatus, during this report the latter of that is of attention. For the dispersion of 1 innovate another is fairly well understood the form of mixers. By cautious choice of speed of agitation in the mixer an optimum efficiency of extraction is obtained at which acceptable levels of mass transfer occur and also the size distribution phase is in controlled limits such that following coalescence of the drops in the settler would not require an improperly long residence time. [1] Such a selection of speed of agitation is based on in laboratory study. The separation phases in a mixer-settler type contactor happen in the settler, which is fundamentally a larger volume part than mixer. The dispersion is allowed to flow from the mixer into the settler and makes a dispersion band or bed which in general consists of two parts. A fluidized bed region in which drops of the dispersed phase settle or sediment through the continuous phase and a packed-bed region in which there is no observable movement of the drops, which are packed closely. Most of the coalescence occurs in the packed bed region and hence the inter face between the packed bed region and the bulk of the dispersed phase is called the active or coalescing interface. The inter phase between the fluidized-bed region and the bulk continuous phase is called the passive or regimenting front. The thickness of the dispersion band depends on the specific throughput (throughput per unit area) of the dispersion phase. Higher specific throughputs give larger dispersion bands. These characteristics of settler are described by the following equation, [2]
$\mathrm{DH}=\mathrm{K}(\mathrm{Qd} / \mathrm{A})^{\mathrm{Y}}$ this equation is used for scale-up purposes.

Where,

$\mathrm{DH}=$ Dispersion band depth

Qd = Throughput of dispersed phase

$\mathrm{A}=$ Area of settler

$\mathrm{Y}=$ Exponent

$\mathrm{K}=$ Constant

The complete separation of phase requires a much long residence time. Within the time allowed in a normal operation complete separation cannot be obtained and this nation of one phase by another is called entrainment.

Different methods have been tried to improve the separation process in the settler. As a law any means of improvement must be capable to increase the mean diameter of the drops. [3] This may be done by:

- Mechanical settling aids.

- The influence of electric fields.

Mechanical settling aids demonstrate fairly useful improvements but care is required in selecting an opposite material for a particular system. Such settling aids include baffles, rafts, wire mesh and Rashchig rings and should be preferentially wetted by the dispersed phase. Due to lack of understanding of the mode in which such materials aid coalescence, the selection of materials becomes not easy and is based more on trial and error. Centrifuging proves fairly effective but is very costly hence its use is limited. Electrostatic /electrical coalesces are more positive in that they are more simply adjustable to suit any system and less costly to operate. The potential/charge generated could be more easily controlled. Pressure drop in the system is not as high as in the Coalescer using mechanical settling acids for this reason pumping costs are very much reduced. [4] 


\section{International Journal of Science and Research (IJSR)}

ISSN (Online): 2319-7064

Index Copernicus Value (2013): 6.14 | Impact Factor (2015): 6.391

\section{Objectives}

The main objectives of electrostatic separation are:

- To improve section separation by using Electro-pulse inductive Coalescer (EPIC), to permit the assembly of enormous droplets.

- By using Lasentec probe device, to see the droplets size inlet and outlet of EPIC.

- By using insulated high voltage electrodes to stop loss of charge in EPIC, to use pulsed DC voltage instead of standard AC.

To improve the contact between the droplets in form and to form easier droplet-droplet coalescence, and then deposit under gravity.

\section{Experimental Works}

\section{Silections and Preparatton of Test Emulsion}

\subsection{Selection of Test Emulsion}

The emulsion technique for crude oil from the oil field contains water significant, proposition of water typically that Removed in crude oil during exporting (2 -3\%), and approximately 500 PPM a salt content in crude oil. For the percent observation the water proportion that was suspended in kerosene is selected at 3\% of (water in oil emulsion), therefore the volume of de-ionized water was $(3 \times 10000) / 100=300 \mathrm{ml}$ of de-ionized water. Note: the quantity of run emulsion was 10L.

\subsection{Preparation of Test Emulsion (Water in oil)}

The preparation of $10000 \mathrm{ml}$ original $\mathrm{W} / \mathrm{O}$ emulsion $\mathrm{WO}$ emulsion is accomplished by mixing $9700 \mathrm{ml}$ of kerosene solution containing 1.5 wt. \% Span $80 \quad(9554.5 \mathrm{ml}$ kerosene and $145.5 \mathrm{ml}$ Span 80 ), with $300 \mathrm{ml}$ of aqueous solution (De-ionized water, $\mathrm{NaCl}$ ) in homogenizer at 7500 rpm during 2 hours as shown in figure (3.2). Changing by composition of oils used to dilute the original emulsion altered the viscosity of the oil phase. Samples of different drop size were prepared by changing the agitation speed of the homogenizer in the range of (6500 to 9000) rpm.

\subsubsection{Effect of Agitation on Emulsion Stability}

The time of settling or emulsion stability ended a linear relationship and the agitation speeds of the Homogenizer, as shown in Figure (3.2.2).The oil phase viscosity dependence on under stirring was the like regardless of agitation speed Figure (3.2.2) it can be seen that the stability of emulsion increased by increased the homogenizer speed; so the agitation speed is selected at $7500 \mathrm{rpm}$, because the time of settling at this speed was $130 \mathrm{~min}$ as shown in fg. 2 and this time was enough to accomplish the experimental work. [7]

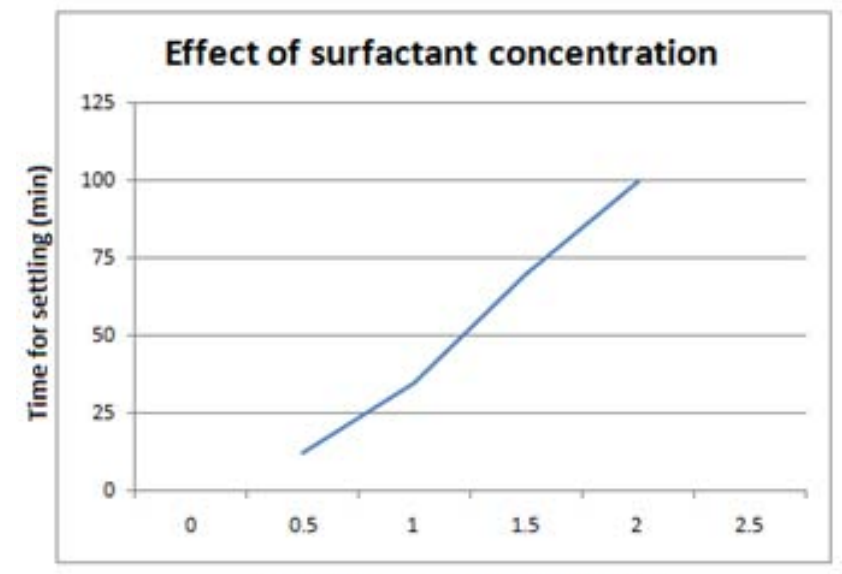

Span 80 concentration (wt\%)

Figure 1: Effect of surfactant concentration

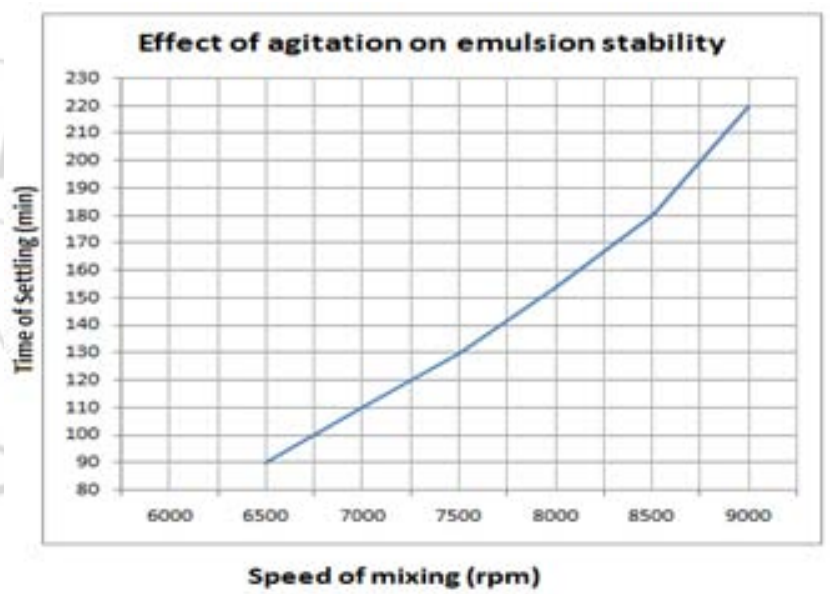

Figure 2: Effect of agitation on emulsion stability

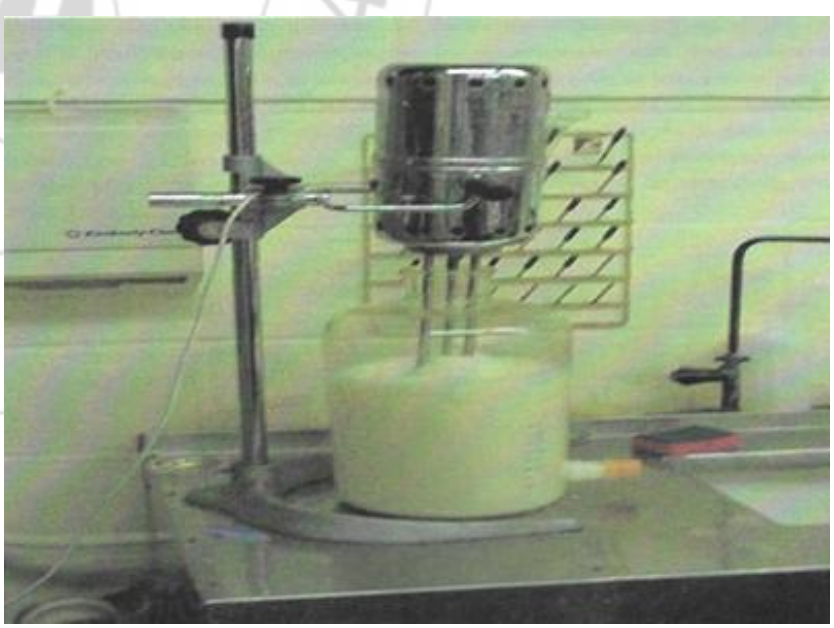

Figure 3: Homogenizer

\subsection{Electrical equipment}

The electrical equipment illustrated in the figure (3.4.3), consists of:

\section{- The Oscilloscope:}

The oscilloscope used for reading the waveform and determining the magnitude of the applied voltage. The equipment was of Hitachi and V-1065A model and can be tuned for both AC and DC voltages.

\section{Volume 5 Issue 5, May 2016}




\section{International Journal of Science and Research (IJSR) \\ ISSN (Online): 2319-7064}

Index Copernicus Value (2013): 6.14 | Impact Factor (2015): 6.391

\section{- The Function Generator:}

The function generator used in order to yield a square signal under various frequencies. It was a FARNEL brand. The output signal can be chosen (square, sinusoidal, etc.) the mark/space ratio can be tuned as well.

\section{- Power Supply:}

Power supply used in order to supply high voltage electricity. The type used is a BRANDENBURG alpha series of 807R model. It can deliver a DC voltage that can be tuned from 0 to $30 \mathrm{kV}$, at $2 \mathrm{~mA}$.

\section{- The Modulator:}

Used for splitting the high voltage signal to produce a pulsed signal. a MAZDA valve PD510 model. With its grid voltage controlled by the signal from the function generator was used for this purpose.

$\mathrm{C}_{1}$ to $\mathrm{C}_{10}$ : All of the connections on the rig are PTFE corrugated tubing with the internal diameter of $9 \mathrm{~mm}$.

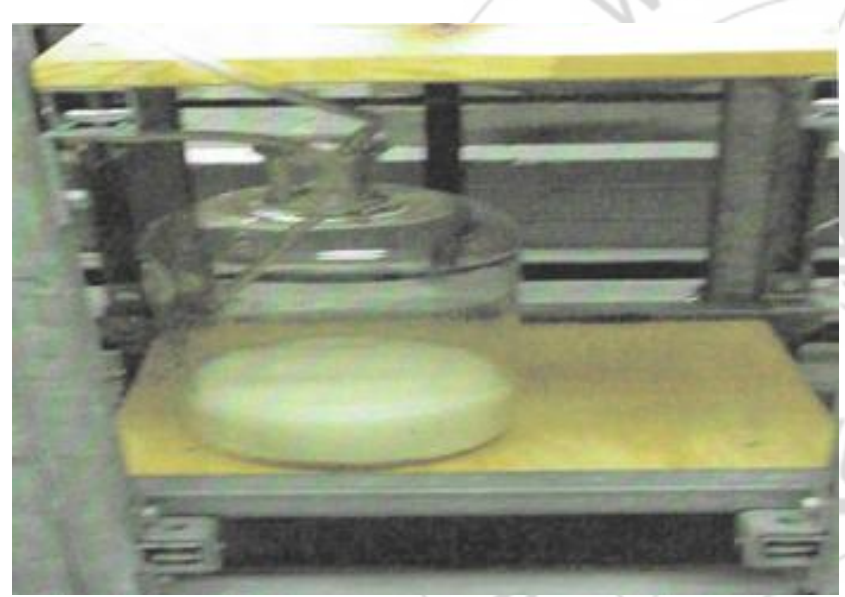

Figure 4: Settler gravity

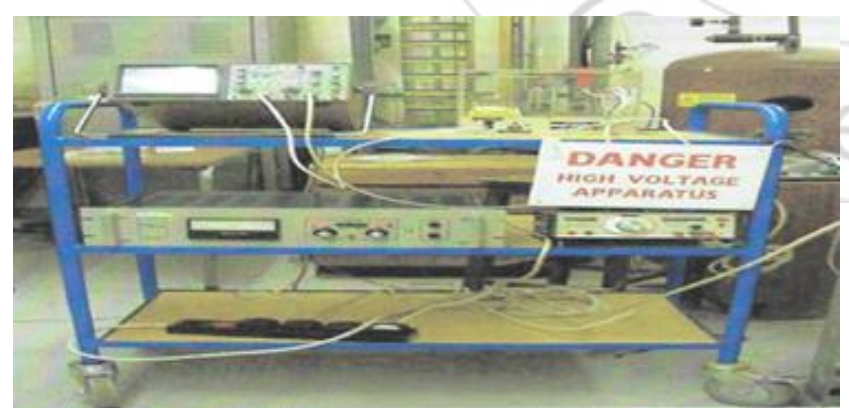

Figure 5: Electrical Equipment

\subsection{Analytical Measurement}

\subsubsection{Lasentec Probe}

Lasentec probe (Focused Beam Reflectance Measurement) measures, in real-time, the rate and the degree of change in

From above table 1, showing the linear relationship between the mean chord length and the frequency, which mean the mean chord length, increased with increase the frequency. both the numbers and the dimension of droplets as they naturally exist in process as shown in figure (3.5.1). Lasentec probe utilizes a patented probe-based design permitting easy installation and virtually maintenance-free operation within existing pipelines and vessels. Lasentec probe technology provides the ability to rapidly define and monitor the relationships between isolated size regions of the droplet population (Concentration of Droplets within Desired Size Rang, percent Undersized, etc.) and process operating conditions (Agitation Rate, Surfactant, Addition etc.), downstream process performance (Stability, Separation Efficiency, etc.) and final product specification (Stability, Homogeneity, Droplet Size, Viscosity, etc.). [8]

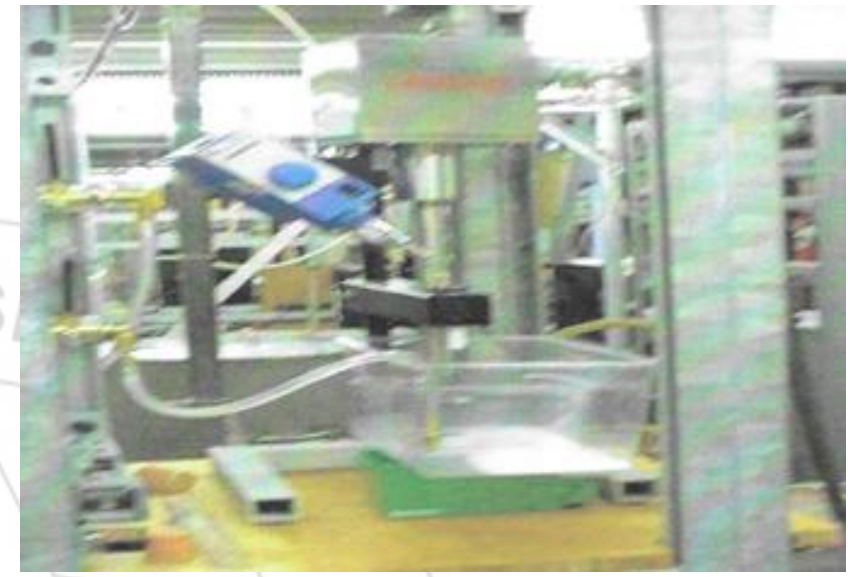

Figure 6: Lasentec Probe

\section{Results and Discussion}

Following are the check conditions execute to the results obtained in this practical except where it is stated.

\section{1 Effect of Pulsed DC Frequency on the Resolution of Water-in-Kerosene Emulsions}

Water-in-Kerosene Emulsions were treated with pulsed DC electric fields of varying frequency applied. The effect of pulsed DC electric field of varying frequency on the mean chord length (microns) is shown in Figure 7. From this Figure, it's apparent that as the frequency of pulsation is increased coalescence also increases. The frequency dependence is strong evidence for the involvement of mean chord length processes. During this study, the graph 7 explains the relationship between the mean chord length and frequency at bound voltage. This study is investigated.

Table 1: Effect of frequency on mean chord length at 1.6

\begin{tabular}{|c|c|}
\multicolumn{2}{|c}{ KV } \\
\hline Means chord length & Frequency at $1.6 \mathrm{kV}$ \\
\hline 96.07 (micron) & $0 \mathrm{~Hz}$ \\
\hline 124.78 (micron) & $50 \mathrm{~Hz}$ \\
\hline 179.19 (micron) & $100 \mathrm{~Hz}$ \\
\hline
\end{tabular}




\section{International Journal of Science and Research (IJSR) \\ ISSN (Online): 2319-7064}

Index Copernicus Value (2013): 6.14 | Impact Factor (2015): 6.391

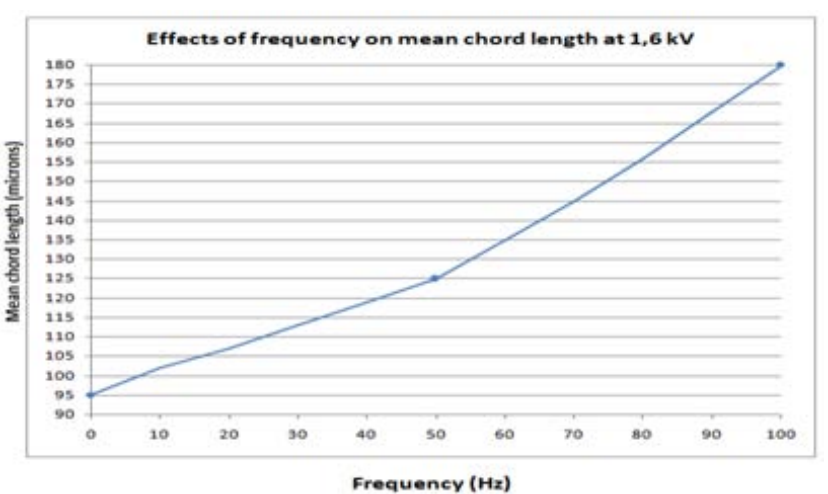

Figure 7: Effect of frequency on mean chord length at 1,6 $\mathrm{kv}$

The settling characteristics of the settler and Coalescer column are form with an increase in mean chord length from 66.66 (microns) at inlet to 179.19 (micron) at $(1.6 \mathrm{kV}$, $100 \mathrm{~Hz}$ ). The coalescence is still by gravity only but the Coalescer column provides an additional area where some droplet growth occurs before the dispersion goes into the settler and this may account for the improved settling characteristics. Previous, workers in this field have not discussed the increases in the mean chord due to the application of electrostatics; workers studying the effect of mechanical settling aids, example Barnea and Mizrah have reported it. They observed, in their study of packed-bed diffuser coalesce, a considerable increase in the exponent. It therefore seems that an increase in drop size as produced by both diffuser- coalesces and electrostatic coalesces is associated with an increase in the exponent of the coalescence characteristics. The residence time of the dispersion is so. Short in the coalesce com-pared to \&rat of the settler, the drops may not have to completely coalesce and drop. Interface may not account for much of the following two causes or both, namely (i) rapid drop-drop coalescence in the coalesce column due to the application of electro-statics and hence rupture of the continuous firm separating the drops.

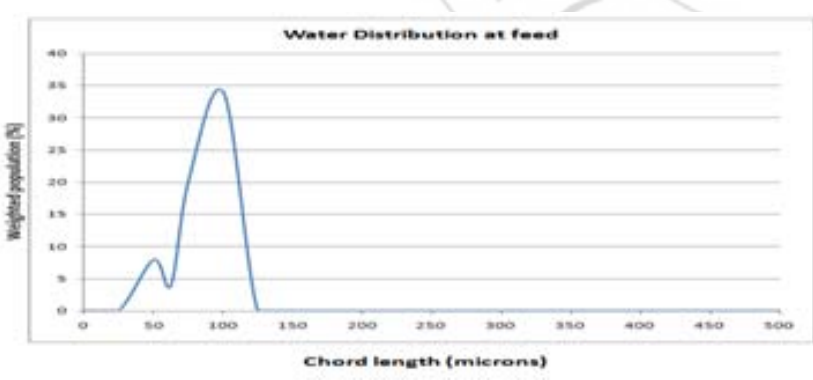

Figure 8: Mean chord length at feed $=66.68$ micron

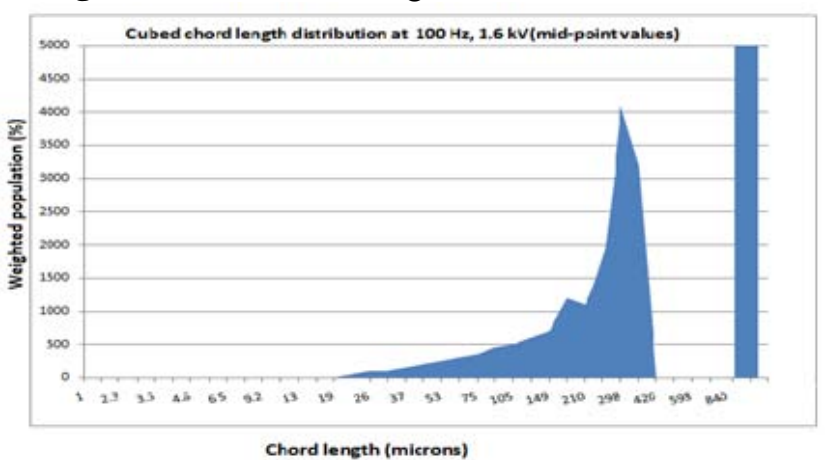

Figure 8: $(5.2 \mathrm{H})$

\section{Conclusions and Recommendations}

After studying this entire thing is that the rate of coalescence in a settler and there for its capacity may be increased significantly by application of electrostatics. The mechanism of electrostatic coalescence seems to be dropdrop coalescence, which increases the size of the drops.

The present study is not extensive enough since parameters like voltage and frequencies, which are important in any study involving electrostatics, could not be measured with the Coalescer used. The full implication of the results may therefore not be realized, although some quantitative analysis has been made to describe the effect of frequency at certain voltage on coalescence, furthermore, the method generating electrostatics used in this study is rather primitive and could be dangerous in industry, however, it has served its purpose will enough in this preliminary study and has highlighted the effect of electrostatics on coalescence. In any further work it will be necessary.

To make measurement of voltage and frequency, so that a more complete quantitative analysis can be made and it will therefore be necessary to design equipment with due consideration of the measuring problem it will also be necessary to determine the size of droplets by Lasentec device so as to assess the influence of frequency at certain voltage on droplets size.

\section{Recommendation for Further Work}

- A detailed study of droplet size is required which might allow for better interpretation of the column performance.

- Should consider the relative merits of DC voltage and frequency for the coalescence of dispersions since this may be significant in industry.

- To reach the optimal frequency, the frequency must be increased.

\section{References}

[1] (P. Hajivand, A. Vaziri, 2015) optimization of demulsified formulation for separation of water from crude oil emulsions, doi.org/10.1590/01046632.20150321s00002755.

[2] Arun K Kota1 and Anish Tuteja published in Asia materials, 2013, "High-efficiency, ultrafast separation of emulsified oil-water mixtures", doi:10.1038/am.2013.34

[3] Arun K. Kota, Gibum Kwon, Wonjae Choi, Joseph M. Mabry \& Anish Tuteja, 2012, "Hydro-responsive membranes for effective oil-water separation", Nature Communications 3, Article number: 1025 doe: 10.1038/ncomms2027, Published 28 August 2012.

[4] Shi, Z., Zhang, W., Zhang, F., Liu, X., Wang, D., Jin, J. \& Jiang, L. Ultrafast separation of emulsified oil/water mixtures by ultrathin free-standing singlewalled carbon nanotube network films. Adv. Mater. 25, 2422-2427 (2013). 


\section{International Journal of Science and Research (IJSR) \\ ISSN (Online): 2319-7064}

Index Copernicus Value (2013): 6.14 | Impact Factor (2015): 6.391

[5] Daaou, M., Bendedouch, D., Water $\mathrm{pH}$ and surfactant addition effects on the stability of an Algerian crude oil emulsion. Journal of Saudi Chemical Society, 16, 333-337, (2012).

[6] Honse, S. O., Ferreira, S. R., Mansur, C. R. E., Lucas, E. F., Gonzalez, G., Separation and characterization of asphaltenes subtractions. Quimica Nova, 35(10), 1991-1994 (2012).

[7] Lucas, E. F., Mansur, C. R. E., Spinelli, L., Queirs, Y. G. C., Polymer science applied to petroleum production. Pure and Applied Chemistry, 81(3) 473494 (2009).

[8] Pacheco, V. F., Spinelli, L., Lucas, E. F., Mansur, C. R. E., Destabilization of petroleum emulsions: Evaluation of the influence of the solvent on additives. Energy \& Fuels, 5, 1659-1666 (2011).

[9] Ramalho, J. B. V. S., Lechuga, F. C., Lucas, E. F., Effect of the structure of commercial poly (ethylene oxide-b-propylene oxide) demulsified bases on the emulsification of water-in-crude oil emulsions: Elucidation of the emulsification mechanism. Quimica Nova, 33(8) 1664-1670 (2010) 